\title{
Sensitivity and vulnerability of water resources in the arid Shiyang River Basin of Northwest China
}

\author{
Long WAN ${ }^{1,2}$, Jun XIA ${ }^{1,3^{*}}$, HongMei BU ${ }^{1}$, Si HONG ${ }^{1,2}$, JunXu CHEN ${ }^{1,2}$, LiKe NING ${ }^{1,2}$ \\ ${ }^{1}$ Key Laboratory of Water Cycle \& Related Land Surface Processes, Institute of Geographic Sciences and Natural Resources \\ Research, Chinese Academy of Sciences, Beijing 100101, China; \\ ${ }^{2}$ Graduate University of Chinese Academy of Sciences, Beijing 100049, China; \\ ${ }^{3}$ State Key Laboratory of Water Resources \& Hydropower Engineering Sciences, Wuhan University, Wuhan 430000, China
}

\begin{abstract}
The sensitivity and vulnerability of water resources to climate change is difficult to assess. In this study, we used a conceptual hydrologic model to investigate the sensitivity of streamflow to climate change. We also proposed a framework to evaluate the vulnerability of water resources in arid regions. We applied this framework to a case study of the Shiyang River Basin in Northwest China. Results showed that the precipitation and streamflow in Shiyang River Basin exhibited no significant trends of change from 1956 to 2010. In the past five decades, however, the temperature increased significantly by $0.37^{\circ} \mathrm{C}$ per decade. According to the sensitivity assessment, a $10 \%$ increase in precipitation and $1^{\circ} \mathrm{C}$ increase in temperature altered mean annual streamflow by averages of $14.6 \%$ and $-0.5 \%$, respectively, from 1988 to 2005 . In the 2000 s, the calculated vulnerability of water resources in Shiyang River Basin was more than 0.95 , indicating severe vulnerability. The increase in the amount of precipitation and the implementation of water-saving measures can reduce the vulnerability of water resources in the future; if precipitation increases by $10 \%$ per decade and the use of irrigation water decreases by $15 \%$ in the 2030 s, the evaluated value of water resources vulnerability will be reduced to 0.79 . However, the region remains highly vulnerable. The proposed framework for vulnerability assessment can be applied to the arid regions in Northwest China, and the results of our efforts can identify adaptation strategies and improve the management of water resources in such regions.
\end{abstract}

Keywords: climate change; streamflow sensitivity; water resources vulnerability; arid regions

Citation: Long WAN, Jun XIA, HongMei BU, Si HONG, JunXu CHEN, LiKe NING. 2014. Sensitivity and vulnerability of water resources in the arid Shiyang River Basin of Northwest China. Journal of Arid Land, 6(6): 656-667. doi: 10.1007/s40333-014-0067-8

Arid regions are among the most fragile ecosystems in the world and suffer the most severe droughts. Therefore, the water resources and ecological systems in arid regions are particularly affected by climate change. In arid regions, climate change may either exacerbate or alleviate existing water stresses caused by population growth, rapid economic development and the expansion of arable land (Perlis et al., 2009; Themnér et al., 2011).

The arid regions in China are mainly located in the northwest of the country and experience serious water shortage (Feng and Cheng, 1998; Li, 2003). In these regions, the sustainable management of water resources under climate change faces several enormous future challenges, including glacial retreat, changes in the amount of available water, overexploitation of water resources and possible ecological problems (Yin, 2006; Shi et al., 2007). To address these climate change-related challenges, studies in the field of water resources management focus on two imperative topics: the first is understanding the sensitivity of hydrological variables, such as streamflow, to climatic change because the economic development, agricultural irrigation and ecosystem balance in Northwest China depend on sustainable water supply (Nijssen et al., 2001; Kang et al., 2003); the second is developing an

*Corresponding author: Jun XIA (E-mail: xiaj@igsnrr.ac.cn) 
integrated index to assess the regional vulnerability of water resources in the face of potential climate change (Liu, 2003).

The Shiyang River Basin is a typical arid inland basin located in Northwest China. In the Shiyang River Basin, the gap between water supply and demand increases as a result of population increase and social economic development (Ji et al., 2006). The unreasonable exploitation and utilization of water resources have seriously deteriorated the ecological environment (Li et al., 2013). As climatic changes complicate and destabilize water supply and demand (Huo et al., 2008), understanding the hydrological responses to these changes and assessing the vulnerabilities of water resources are important for developing sustainable management strategies in this region.

This study investigated the trends in climate variables and streamflow in the Shiyang River Basin from 1956 to 2010. It aims to: (1) comprehensively analyze the hydrologic responses of streamflow regimes to climate change basing on a hydrological model DTVGM (Distributed Time Variant Gain Model); and (2) assess both the vulnerability and the adaptation of water resources to climate change to improve the adaptive capacity of water systems to climate change in the Shiyang River Basin.

\section{Study area and methods}

\subsection{Study area}

The Shiyang River Basin is located in the Hexi Corridor of Gansu and Inner Mongolia, both of which are arid regions located in Northwest China. The basin covers an area of $41,600 \mathrm{~km}^{2}\left(36^{\circ} 29^{\prime}-39^{\circ} 27^{\prime} \mathrm{N}\right.$, $\left.101^{\circ} 41^{\prime}-104^{\circ} 16^{\prime} \mathrm{E}\right)$, with an elevation ranging from $1,200 \mathrm{~m}$ to more than $5,000 \mathrm{~m}$ (Fig. 1). The river originates from the Qilian Mountains and flows northward to the Tengger Desert. In the Qilian Mountains, modern glaciers have developed beyond the elevation of 4,000 m. Aridity ranges from 1 to 6 in the Qilian Mountains and to 10-25 in the northern Minqin Basin. In the middle and lower reaches of the Shiyang River, many areas receive a mean annual precipitation of only $100-200 \mathrm{~mm}$, but evaporation is over $1,500 \mathrm{~mm}$ (as measured by a $20-\mathrm{cm}$ pan). The water resources in the Shiyang River Basin are mainly generated by streamflow from eight tributaries in the Qilian Mountains. These water resources have been intensively exploited since the $1950 \mathrm{~s}$ because of the rapid expansion of human population and fast socialeconomic development. This exploitation has caused many serious problems in this region, including water scarcity and the deterioration of land, vegetation and ecology (Kang et al., 2004).

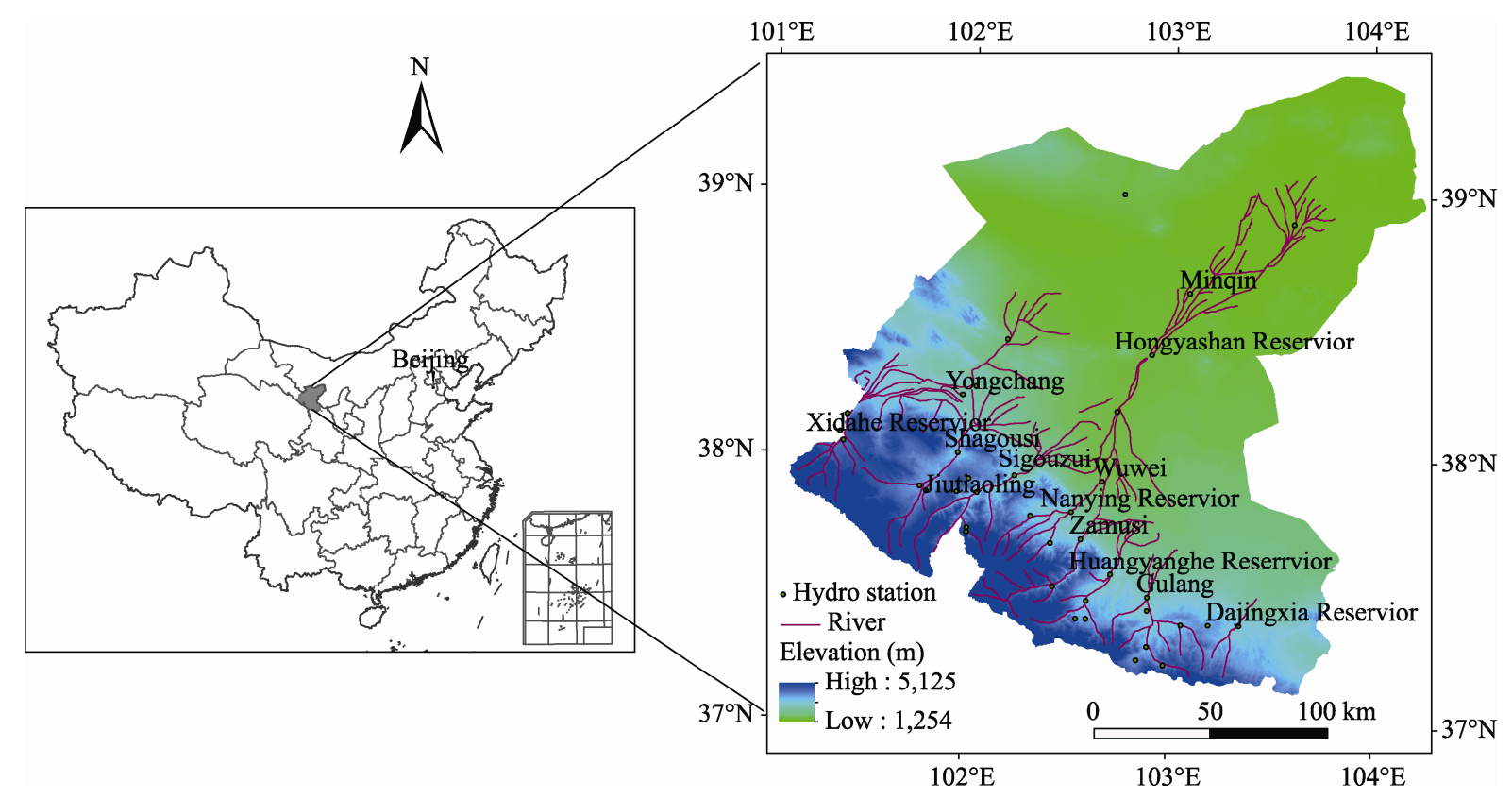

Fig. 1 Location of the Shiyang River Basin in Northwest China 


\subsection{Data}

Daily precipitation and streamflow data were collected from the gauging stations in the eight tributaries of the Shiyang River. For the period of 1956-2010, the data of the maximum/minimum/mean daily air temperatures, relative humidities and wind speeds at the $\mathrm{Wu}-$ wei station were collected to calculate potential evapotranspiration using the Penman-Monteith equation (Allen et al., 1998). These meteorological data were derived from the China Meteorological Administration. Data regarding the annual supply of water resources, the amount of water consumed yearly, human population, irrigation area, areas with drought and other social economic data in the Shiyang River Basin were obtained from the Water Resources Bulletin of Gansu Province, China (Water Conservancy Office of Gansu Province, 2003-2010).

\subsection{Method}

\subsubsection{DTVGM hydrological model}

In this study, DTVGM was applied to the Shiyang River Basin. In the model, water balance is expressed as follows (Xia et al., 2005; Wang et al., 2009):

$$
\Delta A W_{t}=A W_{t+1}-A W_{t}=P_{t}-E T a_{t}-R s_{t}-R s s_{t}-W U_{t} \text {. }
$$

Where AW (mm) is the storage of soil moisture and $\triangle \mathrm{AW}(\mathrm{mm})$ is the change in the storage of soil moisture. The subscripts $t$ and $t+1$ represent the variables at time steps $t$ and $t+1$, respectively. $P(\mathrm{~mm})$ is precipitation and ETa $(\mathrm{mm})$ is actual evapotranspiration. $R s$ and $R s s$ are the surface and subsurface runoff, respectively. $W U$ is net water consumption, including water use, depression storage, ineffective evapotranspiration (mainly with respect to the evaporation of irrigation water) and seepage loss. Given the difficulty of calculating the $W U$ value, this study incorporates $W U$ in the computation of ETa, Rs and Rss by adjusting the parameter values related to human activities. The main hydrologic components of DTVGM are as follows:

The first is with the revised Bagrov evapotranspiration model. The revised Bagrov model can be integrated into DTVGM. Many studies have indicated that actual evapotranspiration is significantly influenced by the antecedent moisture content in soil (Terpstra and Mazijk, 2001). Thus, the revised Bagrov model is written as follows:

$$
\begin{gathered}
d\left(\frac{E T a}{P}\right)=\left(1-\left(\frac{E T a}{E T p}\right)^{N}\right) \times d\left(\frac{P A W}{E T p}\right), \\
\frac{E T a}{E T p}=0, \text { while } \frac{P A W}{E T p}=0 .
\end{gathered}
$$

Where $P A W=K a w \times(A W+P)$. Kaw is a coefficient and is determined by calibrating the model given observed rainfall-runoff data.

The second is with glacial melt. Many studies have determined a strong relationship between snowmelt and air temperature in mountain areas. The snowmelt runoff in DTVGM was calculated using a degree-day model (Hock, 2003). The depth of snowmelt water is given by

$$
M_{t}= \begin{cases}D D F \times\left(T_{a v}-T_{m i t}\right) & T_{a v}>T_{m i t} \\ 0 & T_{a v}<T_{m i t}\end{cases}
$$

Where $\mathrm{M}_{\mathrm{t}}$ is the depth of snowmelt water, $D D F$ is the day-degree factor, $T_{a v}$ is the mean temperature, and $T_{m i t}$ is the threshold temperature beyond which snow presumably melts. In this study, $T_{m i t}$ is $0^{\circ} \mathrm{C} . M_{t}$ was incorporated into $P_{t}$ to calculate the hydrological model.

The value of $D D F$ was between the minimum value $D F_{\min }$ and the maximum value $D F_{\max }$ on 21 December and 21 June. $D D F$ is given by

$D D F=\frac{D F_{\max }+D F_{\min }}{2}+\frac{D F_{\max }-D F_{\min }}{2} \sin \left(\frac{2 \pi}{365}(n-81)\right)$.

The third is with runoff simulation. In DTVGM, rainfall and antecedent moisture content in soil denote runoff. By analyzing the runoff and the soil moisture in several river basins, Xia et al. (2005) determined that the coefficient of surface runoff is time-variant and is a function of the antecedent moisture content in soil. Therefore, the surface runoff $\left(\mathrm{RS}_{\mathrm{t}}\right)$ generated in a basin can be described by

$$
R S_{t}=g_{1}\left(A W_{t} / A W C\right)^{g_{2}} P_{t} .
$$

Where $g_{1}$ and $g_{2}$ are the time-variant gain factors, and $A W C$ is the saturated soil moisture content. To model subsurface runoff $\left(R s s_{t}\right)$, Lee (2007) developed several methods basing on the storage-outflow relationship and linear, quadratic, power law and exponential relationships. In DTVGM, Rss $s_{t}$ is calculated by a linear storage-outflow relationship, which is expressed as follows: 


$$
R S S_{t}=K r\left(A W_{t}+A W_{t+1}\right) / 2
$$

Where $K r$ is the coefficient of subsurface runoff. Therefore, the total runoff $\left(R_{t}\right)$ generated during time $t$ is the sum of the surface and subsurface runoffs:

$$
R_{t}=R s_{t}+R s s_{t}
$$

1.3.2 Nash-Sutcliffe model efficiency coefficient For evaluating the performance of a hydrologic model, the Nash-Sutcliffe efficiency index (Nash and Sutcliffe, 1970 ) is commonly employed. This index is defined as:

$$
E=1-\frac{\sum_{t=1}^{T}\left(Q_{0}^{t}-Q_{m}^{t}\right)^{2}}{\sum_{t=1}^{T}\left(Q_{0}^{t}-\overline{Q_{0}}\right)^{2}} .
$$

Where $Q_{0}$ is the observed discharge, $Q_{m}$ is the modeled discharge, and $Q_{0}^{\mathrm{t}}$ is the observed discharge at time $t$. Nash-Sutcliffe efficiencies can range from $-\infty$ to 1 . An efficiency of $1(E=1)$ denotes the perfect match of the modeled discharge to the observed data. An efficiency of $0(E=0)$ indicates that the model predictions match the mean of the observed data, whereas an efficiency of less than zero $(E<0)$ signifies that the observed mean is a more effective predictor than the model. Essentially, the closeness of the model efficiency to 1 determines the accuracy of the model.

1.3.3 Vulnerability assessment of water resources The Fourth Assessment Report of the Intergovernmental
Panel on Climate Change (2007) defined vulnerability as the degree to which a system is susceptible to and is unable to cope with the adverse effects of climate change, including climate variability and extremes. Vulnerability is a function of the character, magnitude and rate of climate change and is the variation to which a system is exposed. This change affects the sensitivity and adaptive capacity of that system.

Most of the literature on climate impact focuses on vulnerability and the related concepts of exposure, sensitivity and adaptability (Smit and Wandel, 2006; Heltberg and Bonch-Osmolovskiy, 2011). Several factors that influence climate vulnerability include (Cui et al., 2010): (1) Exposure - the degree of climate stress upon a particular unit of analysis. (2) Sensitivity - the degree to which a system will respond, either positively or negatively, to a change in climate. (3) Adaptability - the capacity of a system to adjust in response to either actual or expected climate stimuli, as well as their effects.

Figure 2 illustrates the framework to assess the vulnerability of water resources.

For assessing water vulnerability, researchers have proposed many indices previously (Brown and Matlock, 2011). The most widely used index is the Falkenmark indicator, which is based on water use per

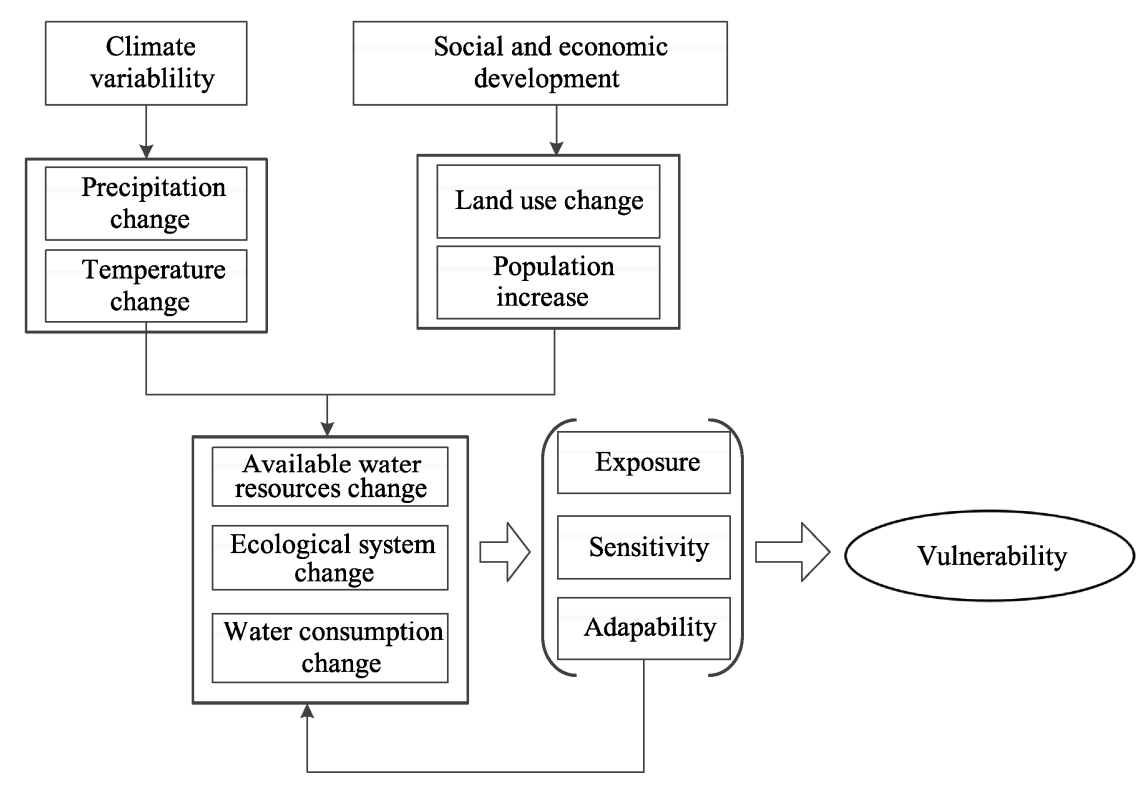

Fig. 2 Framework to assess water vulnerability 
capita (Falkenmark, 1989). Traditionally, the vulnerability of water resources was mainly calculated using methods of weighted arithmetic average. Vörösmarty et al. (2000) developed an index to assess water vulnerability on a global scale; this index was defined as the ratio of water withdrawal (the domestic and industrial sectors and the irrigated agricultural sector) to the total water resources. Sullivan and Huntingford (2009) introduced a climate vulnerability index that integrated geospatial variability, resource quantification, accessibility and property rights, utilization and economic efficiency, the capacities of people and of institutions, and the maintenance of ecological integrity.

Basing on the framework presented in Fig. 2, we expressed the vulnerability of water resources as a function of three components, namely, exposure, sensitivity and adaptability, in our research.

Vulnerability $=($ Exposure $\times$ Sensitivity $) /$ Adaptability.

This equation suggests that the increases in sensitivity and exposure with climate change also enhance vulnerability. It also implies that vulnerability decreases when adaptability increases (Cui et al., 2010).

In arid regions, the system of water resources is characterized by severe drought conditions, a very high degree of water exploitation and severe ecological deterioration. In our study, the vulnerability indicators should reflect the characteristics of the local water system directly. Table 1 presents the vulnerability indicators selected for this study.

Table 1 Indicators of exposure, sensitivity and adaptability for assessment

\begin{tabular}{cl}
\hline Component & \multicolumn{1}{c}{ Indicator } \\
\hline Exposure & Ratio of arable land experiencing drought \\
Sensitivity & $\begin{array}{l}\text { Sensitivity of streamflow to precipitation change } \\
\text { Ratio of the available water resources exploited }(r) ;\end{array}$ \\
Adaptability & $\begin{array}{l}\text { Available water resources per capita }(W P) ; \\
\text { Ratio of ecological water use to the minimum re- } \\
\text { quirements for ecological water }(E R)\end{array}$ \\
\hline
\end{tabular}

In Table 1,

$$
\begin{gathered}
r=\frac{W_{\text {use }}}{W_{\text {available }}}=\frac{W_{\text {use }}}{W_{\text {total }}-W_{\text {eco }}}, \\
W P=\frac{W_{\text {available }}}{\text { Population }}=\frac{W_{\text {total }}-W_{\text {eco }}}{\text { Population }},
\end{gathered}
$$

$$
E R=\frac{W_{\text {eco }}}{W_{\text {eco, } \min }} .
$$

High $W P$ and $E R$ values enhance adaptability; however, adaptability decreases when $r$ is high. Thus, we propose that adaptability is directly proportional to $E R$ and $W P$ but is inversely proportional to $r$.

$$
\text { Adaptability }=\frac{W_{\text {eco }}}{W_{\text {eco,min }}} \times\left(\frac{\frac{W_{\text {available }}}{\text { Population }}}{1000}\right) / r .
$$

Where $r$ is the ratio of the available water resources exploited; $W_{\text {total }}$ is the total supply of water resources in the region; $W_{\text {available }}$ denotes available water resources; $W_{\text {use }}$ represents total water use for agriculture, industries and domestics; $W_{\text {eco }}$ is the amount of ecological water used; and $W_{\text {eco,min }}$ is the minimum requirement for ecological water. The minimum requirement for ecological water is approximately $8.4 \times 10^{8} \mathrm{~m}^{3}$ in the Shiyang River Basin. Falkenmark's water stress index has been widely accepted and used by hydrologists and organizations, such as the Food and Agriculture Organization and the World Bank (Falkenmark, 1989; Brown and Matlock, 2011). Falkenmark suggested that when annual water supply drops to below $1,000 \mathrm{~m}^{3}$ and $500 \mathrm{~m}^{3}$ per person, water scarcity (high water stress) and "absolute scarcity" occur, respectively. Accordingly, we suppose that the threshold of high water stress in this study is $1,000 \mathrm{~m}^{3}$ of available water resources per capita.

We proposed an exponential function to normalize the vulnerability values (Fig. 3) so that they lie between 0 and 1 . In our research, vulnerability was calculated using the following equation:

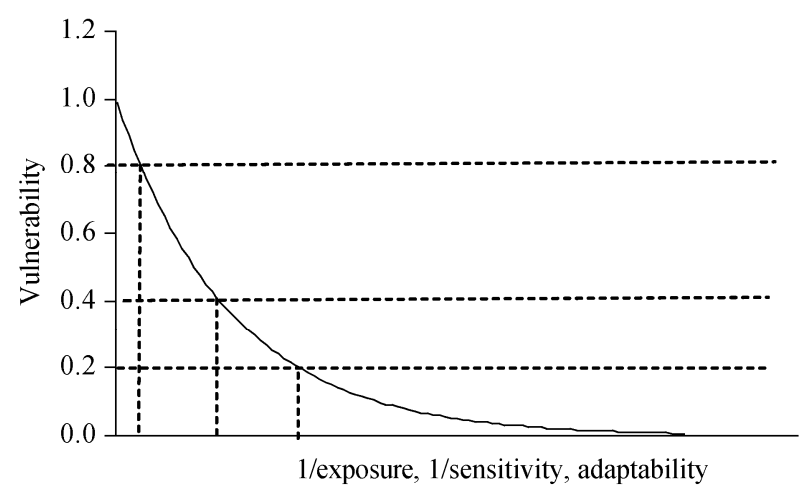

Fig. 3 Exponential relationship between vulnerability and exposure, sensitivity and adaptability 


$$
\text { Vulnerability }=e^{\left(-\frac{k}{\frac{\text { Sensitivity×Exposure }}{\text { Adaptability }}}\right)} .
$$

Where $k$ is the parameter.

Given $r=0.4, W P / 1000=1, E R=1$, Sensitivity=1 and Exposure $=0.1$, the vulnerability value was 0.4 , which represents a high degree of vulnerability (Vörösmarty, 2000). Thus, $k$ was 0.036 . The classification of vulnerability values is shown in Table 2 .

Table 2 Classification of vulnerability values

\begin{tabular}{cc}
\hline Classification & Value range \\
\hline Little to no vulnerability & Vulnerability $\leq 0.1$ \\
Low vulnerability & $0.1<$ Vulnerability $\leq 0.2$ \\
Moderate vulnerability & $0.2<$ Vulnerability $\leq 0.4$ \\
High vulnerability & $0.4<$ Vulnerability $\leq 0.8$ \\
Severe vulnerability & $0.8<$ Vulnerability $\leq 1.0$ \\
\hline
\end{tabular}

\section{Results and discussion}

2.1 Spatial-temporal variability of precipitation and streamflow in Shiyang River Basin from 1956 to 2010

Figure 4 depicts the spatial pattern of mean annual

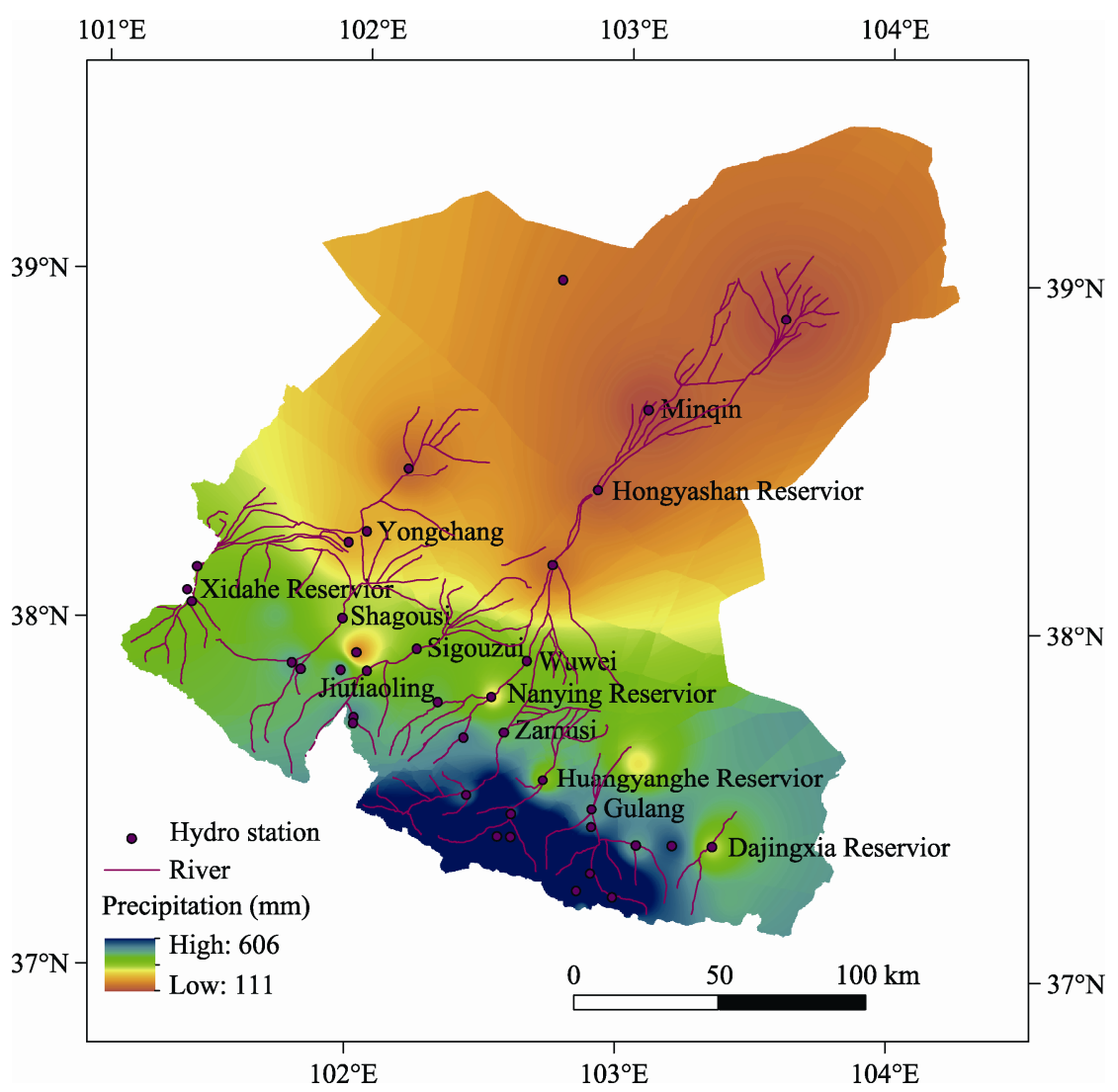

Fig. 4 Spatial distribution of mean annual precipitation in the Shiyang River Basin during 1956-2010 deserts. Kendall, 1975). $103^{\circ} \mathrm{E} \quad 104^{\circ} \mathrm{E}$

precipitation in the Shiyang River Basin. Precipitation values were high in the southern Qilian Mountains, whereas they were lower in the Minqin Basin and in the northern desert regions. Maximum annual precipitation was more than $600 \mathrm{~mm}$ in the upper reaches of the Shiyang River, whereas minimum annual precipitation was only approximately $112 \mathrm{~mm}$ in the northern

The water resources in the Shiyang River Basin are primarily derived from precipitation and glacial melt water from the Qilian Mountains. In this area, the trends in precipitation and total streamflow were investigated using the Mann-Kendall test (Mann, 1945;

According to the test results, no significant trends in annual precipitation or streamflow (at the 95\% confidence level) were found in the Shiyang River Basin. The streamflow values in the 1990s were lower than those in other decades. After 2000, the streamflow in the Shiyang River Basin increased. Water stress in this region can be mitigated (Fig. 5). This result is consistent with previous investigations on the trends in 
precipitation and streamflow in the Shiyang River Basin (Ma et al., 2013).

In our study, we explored the trends in temperature and reference evapotranspiration at the Wuwei station. The temperature at the Wuwei station increased significantly from 1951 to 2010 by $0.37^{\circ} \mathrm{C}$ per decade (using Sen's slope estimator). After 1980, the temperature rose rapidly. From 1956 to 1979, the reference evaporation decreased. As the temperature increased sharply after 1980, the reference evapotranspiration increased significantly. Previous studies also indicated the significant upward warming trend since 1986 in the Shiyang River Basin (Huo et al., 2008). Some studies concluded that there was a signal of climate change from warm-dry to warm-wet in Northwest China after the late 1980s (Shi et al., 2003). But such a shift signal did not occur in the Shiyang River Basin because the precipitation changed insignificantly.

In the lower reaches of the Shiyang River, however, the incoming streamflow of the Hongyashan Reservoir has decreased significantly since the 1970s. In the 1960 s, the incoming streamflow was approximately $4 \times 10^{8}-6 \times 10^{8} \mathrm{~m}^{3}$. After 2000 , the incoming streamflow of this reservoir was much lower at less than $1 \times 10^{8} \mathrm{~m}^{3}$. In 2004, the Hongyashan Reservoir was dried up almost completely for six months. Thus, the ecology in the Shiyang River Basin was at its most fragile state. To protect the ecology in this area, the government implemented a water management plan. After 2006, the incoming streamflow of the Hongya-
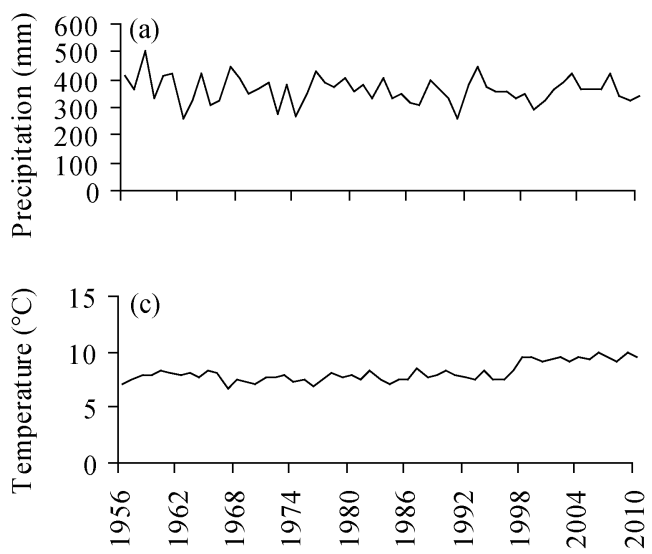

shan Reservoir increased slightly.

\subsection{Sensitivity of the streamflow in the Shiyang River Basin}

To understand the sensitivity of the streamflow to variables of climate change (temperature and precipitation), we developed the conceptual DTVGM hydrological model to simulate daily streamflow in the Shiyang River Basin. The daily values were summed to estimate monthly and annual streamflow. Figure 6 compared the time-series data on predicted and measured streamflow in the Shiyang River Basin.

DTVGM can accurately track the measured monthly and annual streamflow from 1988 to 2005, although some of the predicted peak flows were either slightly lower or higher than the measured data (Fig. 6 ). We calibrated the model manually by adjusting the parameters based on our experience. The most important DTVGM parameters were listed in Table 3. To evaluate the efficiency of DTVGM in predicting monthly and annual flows, we applied the Nash-Sutcliffe coefficient. The coefficient of Nash-Sutcliffe efficiency of monthly predictions and measured streamflow was 0.86 , whereas that of annual streamflow modeling was 0.70 .

The sensitivity of water resources to climate change can be defined as the response of streamflow to a known quantum of climate change (Jones et al., 2006). Previous studies used empirical approaches to evaluate streamflow response to climate change in the Shiyang River Basin (Ma et al., 2008; Li et al., 2014). Snowmelt streamflow was considered sensitive to
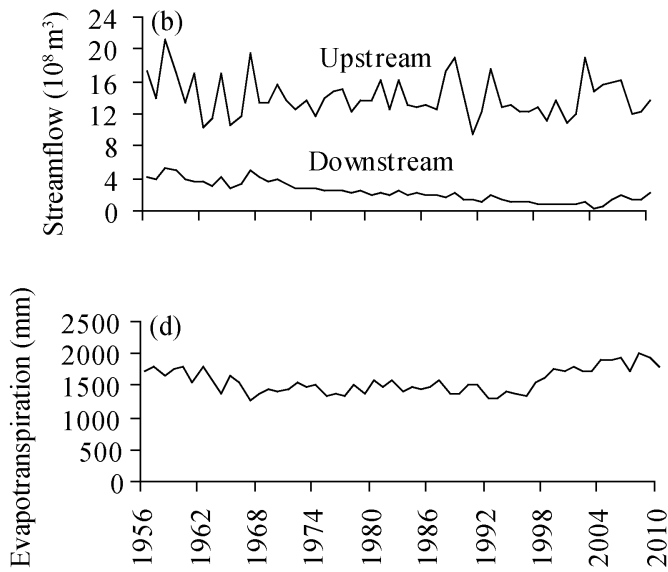

Fig. 5 Trends in the hydrological variables for the upper reaches of the Shiyang River during 1956-2010 


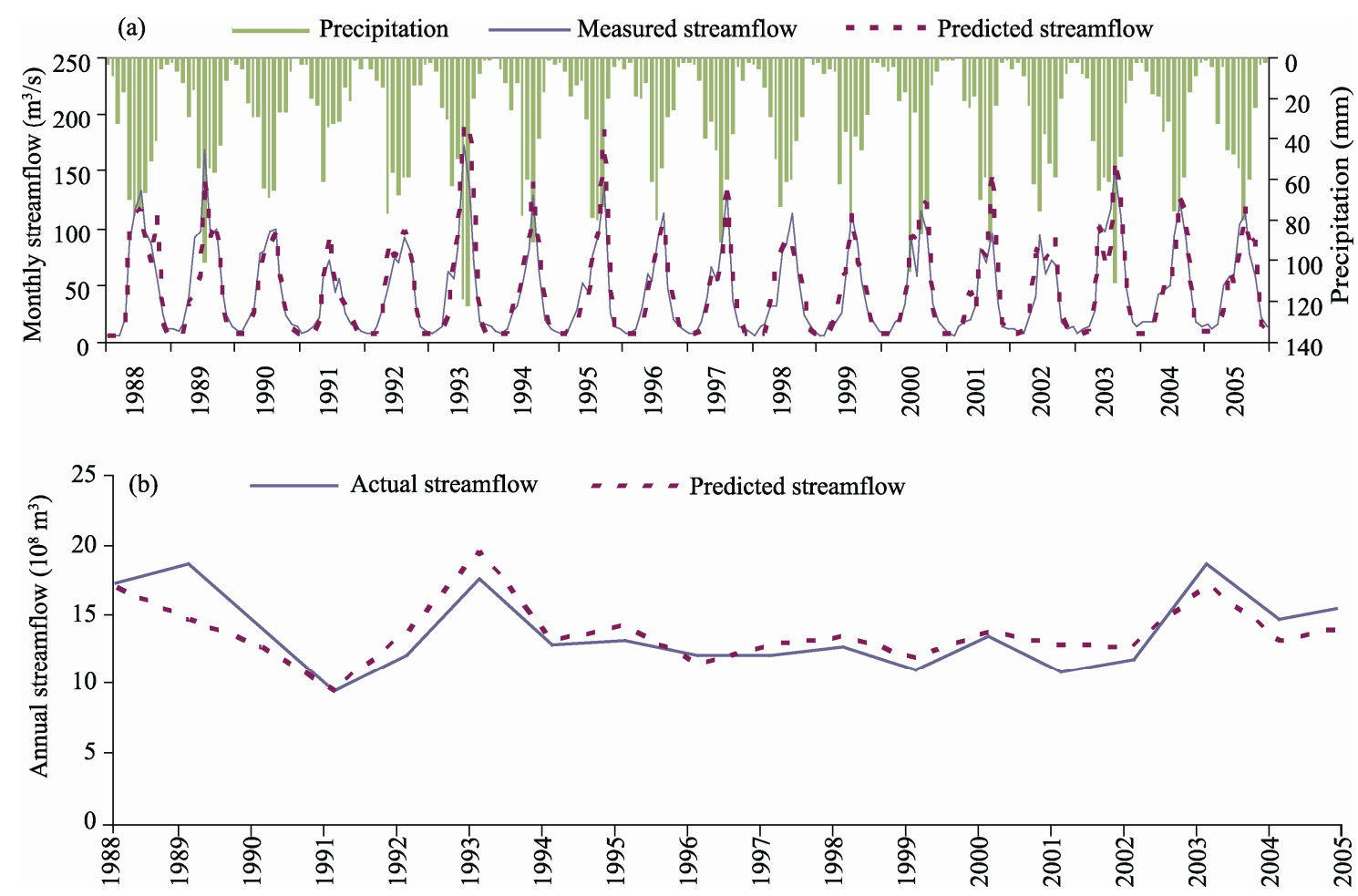

Fig. 6 Modeling of monthly and annual streamflow during 1988-2005 in the Shiyang River Basin based on DTVGM

Table 3 Parameter values for DTVGM

\begin{tabular}{lcc}
\hline \multicolumn{1}{c}{ Parameter } & Description & Value \\
\hline Time-variant gain factor related to surface runoff generation & $g_{1}$ & 0.60 \\
Time-variant gain factor related to soil moisture content & $g_{2}$ & 0.20 \\
Storage-outflow coefficient related to interflow runoff generation & $\mathrm{Kr}$ & 0.50 \\
Coefficient of actual evapotranspiration & Kaw & 0.85 \\
Field capacity of soil & wmi & 0.25 \\
\hline
\end{tabular}

climate change in arid regions of Northwest China (Wang and $\mathrm{Li}, 2006$ ). So we used a hydrological model to investigate the streamflow response to both precipitation and temperature changes in the Shiyang River Basin.

Figure 7 showed the mean changes in annual streamflow as a result of climate change. In DTVGM, the mean sensitivity of changes in mean annual streamflow to every $10 \%$ change in mean annual precipitation was $14.6 \%$. For every $1{ }^{\circ} \mathrm{C}$ increase in mean annual temperature, the mean sensitivity was $-0.5 \%$.

Streamflow is generally more sensitive to changes in precipitation than to those in temperature (Rowe et al., 1994). If precipitation increases by $10 \%$, the streamflow would increase by $10.9 \%-17.0 \%$. However, if temperature increases by $1^{\circ} \mathrm{C}$, the streamflow would increase by $-2.2 \%-2.1 \%$ as a result of the increases in reference evapotranspiration and snowmelt water (Li et al., 2013). The sensitivity of streamflow to changes in precipitation also increased in the 2000s. After 2000 , a $10 \%$ change in precipitation altered streamflow by $15 \%-17 \%$. Before 2000 , this effect was estimated to be only $10 \%-15 \%$.

\subsection{Assessment of water vulnerability in the Shi- yang River Basin}

2.3.1 Significant increase in water consumption from 1949 to 2010

To improve water management, we must enrich our understanding of the relationships between water resources and population dynamics. From 1950 to 2010, the population in the Shiyang River Basin grew by an average of $2.4 \times 10^{4}$ people per year (Fig. 8 ). 

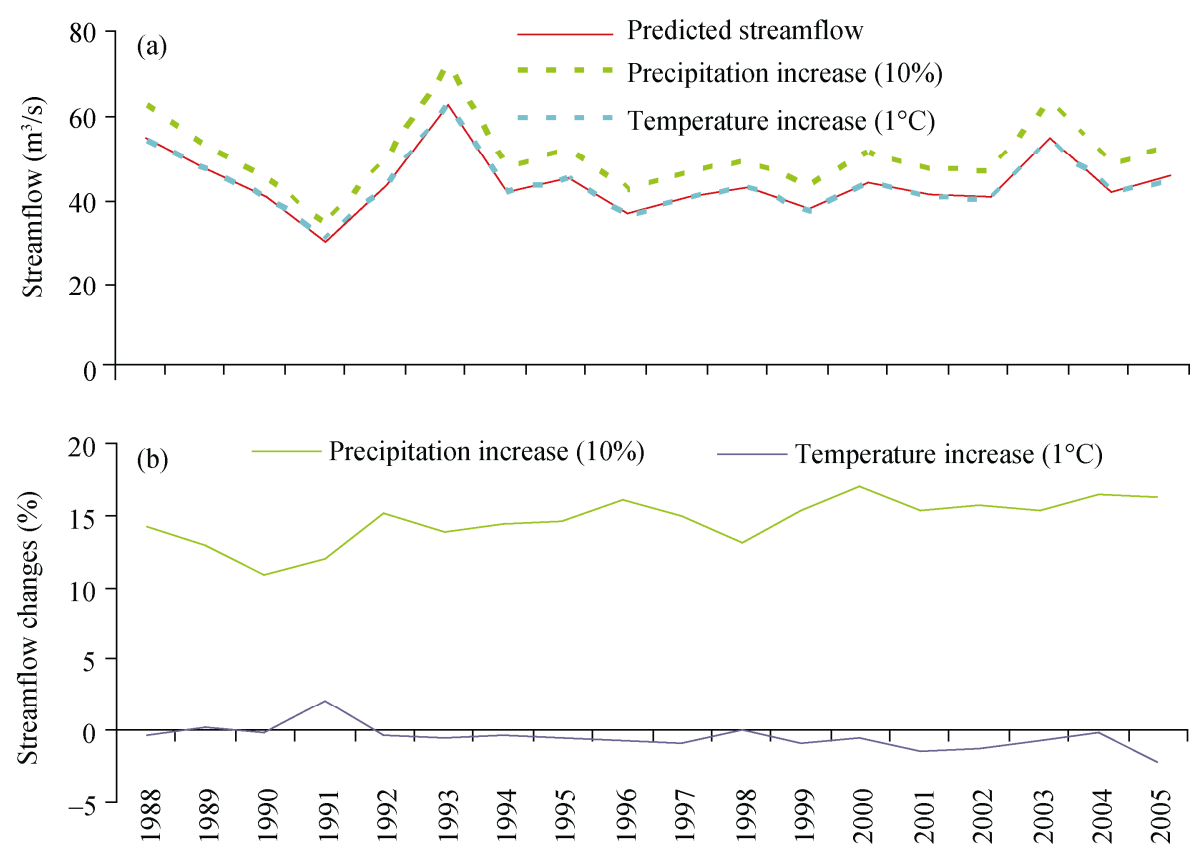

Fig. 7 Sensitivity of streamflow response to precipitation/temperature change in the Shiyang River Basin during 1988-2005

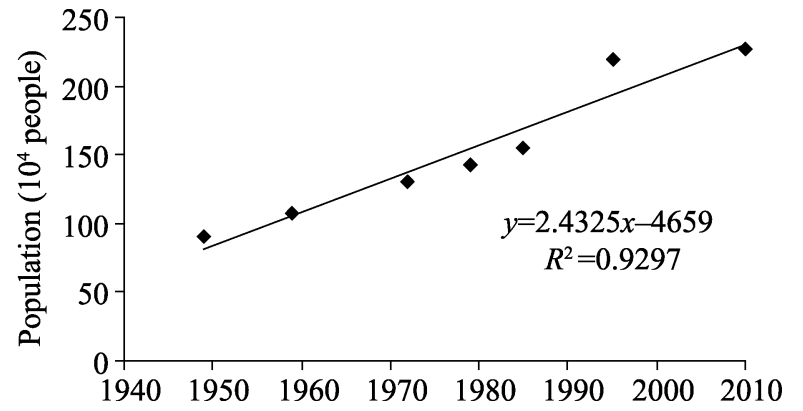

Fig. 8 Population increase in the Shiyang River Basin during 1949-2010

In the Shiyang River Basin, agriculture consumed the most water resources, constituting roughly $85 \%$ of freshwater withdrawals. In the 1950s, agricultural water use was only approximately $14 \times 10^{8}-15 \times 10^{8} \mathrm{~m}^{3}$, but it increased to approximately $23 \times 10^{8} \mathrm{~m}^{3}$ in the 2000s. Total water use in the Shiyang River Basin could reach $25 \times 10^{8}-26 \times 10^{8} \mathrm{~m}^{3}$. Rapid population growth and the expansion of arable land increased water consumption substantially. Nevertheless, water use in this region was far greater than the available supply of water resources.

2.3.2 Assessment of the vulnerability of water resources in the Shiyang River Basin

The vulnerability assessment of water resources is complex in the arid regions of Northwest China. Wu et al. (2013) used a dynamic model for vulnerability assessment of regional water resources in Bayingolin of China. Zhang et al. (2012) assessed the water vulnerability in the Shiyang River Basin with the "Water Poverty Index". But these indicators were seldom linked to climate change, and it was difficult to determine their weights.

Basing on a new framework, we assessed the vulnerability of water resources to climate change in the Shiyang River Basin. The indicators of exposure, sensitivity and adaptability were calculated, as given in Table 4. As a result of high water consumption, the exploitation and utilization of water resources in this region was high in the 2000s, and the ratio of the water resources exploited in the Shiyang River Basin was over $150 \%$. This value was much higher than the mean ratio of water resources utilized by dry land worldwide (30\%; Wang and Cheng, 2000). The intensive exploitation of water resources in the lower reaches of the Shiyang River has highly depleted the supply of ecological water (Ma et al., 2008). In the 2000 s, the available ecological water met only $17 \%$ of the basic ecological requirements in the Shiyang River Basin. Furthermore, pressure from the population can reduce available water resources per capita significantly. Available water resources per capita decreased from $700 \mathrm{~m}^{3}$ to approximately $300-400 \mathrm{~m}^{3}$ per capita 
from 2003 to 2010. From 2008 to 2010, a large area suffered severe drought and water scarcity. Consequently, exposure increased. In 2000s, the average area ratio of the land experiencing drought to arable land was $12 \%$. With respect to the factors in the vulnerability of water resources, exposure and sensitivity in the Shiyang River Basin were high, whereas adaptability was very low. Based on Eq. 13, the vulnerability values of water resources in the Shiyang River Basin were more than 0.95, which represented severe vulnerability (Table 5 ).

For comparing the assessments of future vulnerability, two scenarios were generated as follows:

(1) Scenario 1 (the 2030s): Studies have shown that in the future, precipitation in the Shiyang River Basin supposedly continues to increase (Wang et al., 2012). If the precipitation increases by $10 \%$ per decade, the water resources in the Shiyang River Basin will increase by $15.9 \%$ per decade according to the sensitivity of streamflow to precipitation change. In the 2030s, the water resources will reach approximately $25 \times 10^{8} \mathrm{~m}^{3}$.

(2) Scenario 2 (the 2030s): For reducing water vulnerability in the Shiyang River Basin, adaptation measures should also be implemented. For instance, the use of water-saving technologies has improved the efficiency of irrigation water use in the Shiyang River Basin. In our study, we infer that the use of irrigation water in the Shiyang River Basin will decrease by $15 \%$ in the 2030 s.

The impact of climate change on water resources can be expressed by the exposure, sensitivity and adaptation indicators. The increasing precipitation and the decreasing use of irrigation water are expected to enhance water availability and reduce water consumption in the 2030s. Table 5 indicates that in both scenarios 1 and 2, water vulnerability will be reduced in the future as a result of precipitation increase and water-saving technology. The area ratio of the land experiencing drought to arable land in the future is calculated according to the percentage of aridity anomaly in that year. If the percentage of aridity anomaly in the 2030s is similar to that of a certain historical year, we consider the area ratio of the land experiencing drought to arable land to be similar. The results indicated that the exposure in the region decreases in the 2030s because of the expected significant increase in precipitation. In the future, water exploitation will

Table 4 Calculation of the indicators of water vulnerability in the Shiyang River Basin

\begin{tabular}{|c|c|c|c|c|c|}
\hline \multirow[b]{2}{*}{ Period } & \multirow{2}{*}{$\begin{array}{c}\text { Exposure } \\
\begin{array}{c}\text { Ratio of arable land } \\
\text { experiencing drought }\end{array}\end{array}$} & \multirow{2}{*}{$\begin{array}{c}\text { Sensitivity } \\
\begin{array}{c}\text { Sensitivity of streamflow } \\
\text { to precipitation change }\end{array}\end{array}$} & \multicolumn{3}{|c|}{ Adaptability } \\
\hline & & & $\begin{array}{c}\text { Ratio of the available } \\
\text { water resources ex- } \\
\text { ploited }(r)\end{array}$ & $\begin{array}{l}\text { Available water } \\
\text { resources per } \\
\text { capita }\left(\mathrm{m}^{3}\right)\end{array}$ & $\begin{array}{c}\text { Ratio of ecological water use to } \\
\text { minimum requirements for } \\
\text { ecological water }(E R)\end{array}$ \\
\hline 2003 & 0.047 & 1.54 & 1.57 & 703 & 0.07 \\
\hline 2004 & 0.059 & 1.64 & 2.18 & 503 & 0.02 \\
\hline 2005 & 0.122 & 1.63 & 2.20 & 538 & 0.14 \\
\hline 2008 & 0.144 & 1.63 & 3.60 & 316 & 0.15 \\
\hline 2009 & 0.229 & 1.72 & 3.16 & 331 & 0.17 \\
\hline 2010 & 0.139 & 1.57 & 2.71 & 401 & 0.47 \\
\hline Average in the $2000 \mathrm{~s}$ & 0.123 & 1.63 & 2.57 & 465 & 0.17 \\
\hline 2030s (Scenario 1) & 0.050 & 1.59 & 1.21 & 747 & 0.84 \\
\hline 2030s (Scenario 2) & 0.050 & 1.59 & 1.40 & 747 & 0.44 \\
\hline
\end{tabular}

Note: The implications of Scenario 1 and Scenario 2 are as stated in the text of part 2.3.2.

Table 5 Results of the assessments of vulnerability in the 2000 s and the 2030 s

\begin{tabular}{|c|c|c|c|c|c|}
\hline & Exposure & Sensitivity & Adaptability & Vulnerability & Degree of vulnerability \\
\hline $2000 \mathrm{~s}$ & 0.12 & 1.63 & 0.04 & $>0.95$ & Severe \\
\hline 2030s (Scenario 1) & 0.05 & 1.59 & 0.23 & 0.89 & Severe \\
\hline 2030s (Scenario 2) & 0.05 & 1.59 & 0.51 & 0.79 & High \\
\hline
\end{tabular}

Note: The implications of Scenario 1 and Scenario 2 are as stated in the text of part 2.3.2. 
decrease when the supply of available water is increased and when the amount of water used for agriculture is saved. However, the water exploitation ratios still exceed $100 \%$ in the two provided scenarios. In the 2030s, the availability of ecological water for use will meet $44 \%$ and $84 \%$ of the basic requirements for ecological water resources in scenarios 1 and 2, respectively. However, such values remain inadequate to address these basic requirements. In the 2030s, available water resources per capita will increase to more than $700 \mathrm{~m}^{3}$. As a result, the vulnerability values determined for scenarios 1 and 2 will be reduced to 0.89 and 0.79 . The water resources in the Shiyang River Basin will still be highly vulnerable; thus, early adaptation measures must be implemented immediately in response to climate change.

\section{Conclusions}

In the research fields of hydrology and water management, the assessment of sensitivity and vulnerability in arid regions remains problematic. This study comprehensively assessed the sensitivity and vulnerability of water resources in the Shiyang River Basin, a typical arid inland river basin using the nonlinear hydrological model DTVGM.

From 1988 to 2005, the sensitivity of water resources to climate change was assessed by using the conceptual hydrological model DTVGM. The findings indicated that streamflow was more sensitive to changes in precipitation rather than to those in temperature. A $10 \%$ change in precipitation altered streamflow by $10 \%-17 \%$ in the Shiyang River Basin, whereas every $1{ }^{\circ} \mathrm{C}$ change in temperature altered annual streamflow by only $-2.2 \%-2.1 \%$.

The results of the assessment of water vulnerability in the Shiyang River Basin indicated that water resources in this region suffered low adaptability and severe vulnerability in the 2000s. During this period, the vulnerability values were more than 0.95 (severe vulnerability). If precipitation increases by $10 \%$ per decade and the use of irrigation water use decreases by $15 \%$ in the $2030 \mathrm{~s}$, the calculated vulnerability value of water resources will be reduced to 0.79 (high vulnerability). Nonetheless, the regional vulnerability of water resources may remain high in the future, al- though precipitation may increase and water-saving measures will reduce vulnerability to some extent. Therefore, adaptation measures should be implemented immediately to reduce the vulnerability of water resources in the Shiyang River Basin.

\section{Acknowledgments}

This work was supported by the National Basic Research Program of China (2012CB956204, 2010CB428406) and CAS-CSIRO Cooperative Research Program (GJHZ1223).

\section{References}

Allen R G, Pereira L S, Raes D, et al. 1998. Crop evapotranspiration Guidelines for computing crop water requirements - FAO Irrigation and drainage paper 56. Rome: FAO.

Brown A, Matlock M D. 2011. A review of water scarcity indices and methodologies. In: The Sustainability Consortium. USA: University of Arkansas.

Cui G, Lee S, Lee W, et al. 2010. Vulnerability Assessment of Water Resources to Climate Change Using GIS. In: 2010 ESRI International User Conference. San Diego: Esri, 1-6.

Falkenmark M. 1989. The massive water scarcity now threatening Africa: why isn't it being addressed? Ambio, 18(2): 112-118.

Feng Q, Cheng G D. 1998. Current situation, problems and rational utilization of water resources in arid north-western China. Journal of Arid Environments, 40(4): 373-382.

Heltberg R, Bonch-Osmolovskiy M. 2011. Mapping vulnerability to climate change. World Bank, Washington,USA. [2013-09-01]. http://documents.worldbank.org/curated/en/2011/01/13710247/map ping-vulnerability-climate-change.

Hock R. 2003. Temperature index melt modelling in mountain areas. Journal of Hydrology, 282(1): 104-115.

Huo Z L, Feng S Y, Kang S Z, et al. 2008. Effect of climate changes and water-related human activities on annual stream flows of the Shiyang river basin in arid north-west China. Hydrological Processes, 22(16): 3155-3167.

Ji X B, Kang E, Chen R S, et al. 2006. The impact of the development of water resources on environment in arid inland river basins of Hexi region, Northwestern China. Environmental Geology, 50(6): 793-801.

Jones R N, Chiew F H, Boughton W C, et al. 2006. Estimating the sensitivity of mean annual runoff to climate change using selected hydrological models. Advances in Water Resources, 29(10): 1419-1429.

Kang S Z, Davies B, Shan L, et al. 2003. Water-saving Agriculture and Sustainable Use of Water and Land Resources. Xi'an: Shaanxi Science and Technology Press.

Kang S Z, Su X L, Tong L, et al. 2004. The impacts of human activities on the water-land environment of the Shiyang River basin, an arid 
region in northwest China. Hydrological Sciences Journal, 49(3): 413-427.

Kendall M G. 1975. Rank Correlation Methods. London: Charles Griffin and Company Limited.

Lee D H. 2007. Testing a conceptual hillslope recession model based on the storage-discharge relationship with the Richards equation. Hydrological Processes, 21(23): 3155-3161.

Li B F, Chen Y N, Chen Z S. 2013. Variations of temperature and precipitation of snowmelt period and its effect on runoff in the mountainous areas of Northwest China. Journal of Geographical Sciences, 23(1): 17-30.

Li F M, Zhu G Q, Guo C X. 2013. Shiyang River ecosystem problems and countermeasures. Agricultural Sciences, 4(2): 72-78.

Li P, Xu J H, Chen Z S, et al. 2014. Impact of climate change and human activity on the runoff in the upper reaches of the Shiyang River, Northwest China. PeerJ PrePrints, 1-13.

Li X. 2003. Pressure of water shortage on agriculture in arid region of China. Chinese Geographical Science, 13(2): 124-129.

Liu C Z. 2003. The vulnerability of water resources in Northwest China. Journal of Glaciology and Geocryology, 25(6): 309-314.

Perlis A, Castañeda F, Czudek R, et al. 2007. Forests and Water. Rome: FAO.

Ma G J, Liu J D, Lin D, et al. 2008. Status of water use and its eco-environmental effects in Shiyang River basin. Journal of Desert Research, 28(3): 592-597.

Ma J Z, Chen L H, He J H, et al. 2013. Trends and periodicities in observed temperature, precipitation and runoff in a desert catchment: case study for the Shiyang River Basin in Northwestern China. Water and Environment Journal, 27(1):86-98.

Ma Z M, Kang S Z, Zhang L, et al. 2008. Analysis of impacts of climate variability and human activity on streamflow for a river basin in arid region of northwest China. Journal of Hydrology, 352(3-4): 239-249.

Mann H B. 1945. Nonparametric tests against trend. Econometrica, 13(3): 245-259.

Nash J E, Sutcliffe J V. 1970. River flow forecasting through conceptual models part I-A discussion of principles. Journal of Hydrology, 10(3): 282-290.

Nijssen B, O'Donnell G M, Hamlet A F, et al. 2001. Hydrologic sensitivity of global rivers to climate change. Climatic Change, 50(1-2): 143-175.

Rowe C M, Kuivinen K C, Flores-Mendeza F. 1994. Sensitivity of streamflow to climate change: a case study for Nebraska. Great Plains Research, 4: 27-29.

Shi Y F, Shen Y P, Li D L, et al. 2003. Discussion on the present climate change from warm-dry to warm-wet in Northwest China. Quaternary Sciences, 23(2): 152-164.

Shi Y F, Shen Y P, Kang E, et al. 2007. Recent and future climate change in northwest China. Climatic Change, 80(3-4): 379-393.

Smit B, Wandel J. 2006. Adaptation, adaptive capacity and vulnerability. Global Environmental Change, 16(3): 282-292.
Sullivan C A, Huntingford C. 2009. Water resources, climate change and human vulnerability. In: The $18^{\text {th }}$ World IMACS/MODSIM Congresss. Cairns: Modelling and Simulation Society of Australia and New Zealand, 3984-3990.

Terpstra J, Mazijk A. 2001. Computer aided evaluation of planning scenarios to assess the impact of land-use changes on water balance. Physics and Chemistry of the Earth, Part B: Hydrology, Oceans and Atmosphere, 26(7): 523-527.

The Fourth Assessment Report of the Intergovernmental Panel on Climate Change. 2007. Working Group II: Impacts, Adaptation and Vulnerability. [2013-10-13]. http://www.ipcc.ch/ipccreports/tar/wg2 /index.php?idp=8.

Themnér A, Swain A, Bali Swain R, et al. 2011. Climate Change and the Risk of Violent Conflicts in Southern Africa. South Africa: Global Crisis Solutions.

Vörösmarty C J, Green P, Salisbury J, et al. 2000. Global water resources: vulnerability from climate change and population growth. Science, 289(5477): 284-288.

Wang G, Cheng G. 2000. The characteristics of water resources and the changes of the hydrological process and environment in the arid zone of northwest China. Environmental Geology, 39(7): 783-790.

Wang G S, Xia J, Chen J. 2009. Quantification of effects of climate variations and human activities on runoff by a monthly water balance model: A case study of the Chaobai River basin in northern China. Water Resources Research, 45(7): 1-12.

Wang J, Li S. 2006. Effect of climatic change on snowmelt runoffs in mountainous regions of inland rivers in Northwestern China. Science in China: Series D Earth Sciences, 49(8): 881-888.

Wang Z, Ficklin D L, Zhang Y Y. 2012. Impact of climate change on streamflow in the arid Shiyang River Basin of northwest China. Hydrological Processes, 26(18): 2733-2744.

Water Conservancy Office of Gansu Province, China. 2003-2010. Water Resources Bulletin of Gansu Province from 2003 to 2010. Lanzhou: Gansu Water Resources Bureau.

Wu G Y, Li L H, Ahmad S, et al. 2013. A dynamic model for vulnerability assessment of regional water resources in arid areas: a case study of Bayingolin, China. Water Resources Management, 27: 3085-3101.

Xia J, Wang G S, Tan G, et al. 2005. Development of distributed time-variant gain model for nonlinear hydrological systems. Science in China Series D: Earth Sciences, 48(6): 713-723.

Yin Y Y. 2006. Vulnerability and adaptation to climate variability and change in western China. In: A Final Report Submitted to Assessments of Impacts and Adaptations to Climate Change (AIACC). Meteorological Service of Canada, Downsview, Ontario, Canada.

Zhang R J, Zheng H D, Tan M L, et al. 2012. The assessment of water stress with the Water Poverty Index in the Shiyang River Basin in China. Environmental Earth Sciences, 67(7): 2155-2160. 